\title{
Women's Leadership in Saudi Arabian Higher Education, Change of Society
}

\author{
Riam Almaqrn \\ University of Nottingham
}

\begin{abstract}
.
The voices of women in Saudi Arabia in positions of leadership are increasingly speaking out particularly since the launch of Saudi vision 2030, where bright individuals shine in the recent new world of social media and in high positions, including academia. Overall, little scholarly attention has been paid to the role of Saudi women in leadership and decision-making positions within universities. This qualitative narrative study has been through a pilot, to test the research instruments prior to the main research being conducted. The study has focused on the life and work stories of Saudi women leaders and the opportunities, barriers and support experienced as they achieved leadership positions in higher-education institutions It has not been possible, within the practical and institutional limitations

of this study to explore the experiences of Saudi women leaders in other governmental, economic and legal sectors in the Kingdom. The research was however based on the presumption that gender-cultural traditions will generally impact negatively upon women, restricting the opportunity, supported by ability, to access positions of leadership and responsibility in higher education. The main findings were emerged into four key themes, namely the need for an academic degree, visibility in the working environment, traditional societal view of gender roles and institutional barriers.
\end{abstract}

Keywords: Education, Educational leadership, women in higher education. 